\title{
Metal-Free Photoredox-Catalyzed, Formal C-H/C-H Coupling of Arenes Enabled by Interrupted Pummerer Activation
}

DOI:

10.1038/s41929-019-0415-3

\section{Document Version}

Accepted author manuscript

Link to publication record in Manchester Research Explorer

Citation for published version (APA):

Aukland, M., Siauciulis, M., West, A., Perry, G., \& Procter, D. (2020). Metal-Free Photoredox-Catalyzed, Formal $\mathrm{C}-\mathrm{H} / \mathrm{C}-\mathrm{H}$ Coupling of Arenes Enabled by Interrupted Pummerer Activation. Nature Catalysis, 3, 163-169. https://doi.org/10.1038/s41929-019-0415-3

\section{Published in:}

Nature Catalysis

\section{Citing this paper}

Please note that where the full-text provided on Manchester Research Explorer is the Author Accepted Manuscript or Proof version this may differ from the final Published version. If citing, it is advised that you check and use the publisher's definitive version.

\section{General rights}

Copyright and moral rights for the publications made accessible in the Research Explorer are retained by the authors and/or other copyright owners and it is a condition of accessing publications that users recognise and abide by the legal requirements associated with these rights.

\section{Takedown policy}

If you believe that this document breaches copyright please refer to the University of Manchester's Takedown Procedures [http://man.ac.uk/04Y6Bo] or contact uml.scholarlycommunications@manchester.ac.uk providing relevant details, so we can investigate your claim.

\section{OPEN ACCESS}




\title{
Metal-Free Photoredox-Catalyzed, Formal C-H/C-H Coupling of Arenes Enabled by
}

\author{
Interrupted Pummerer Activation
}

Miles H. Aukland, Mindaugas Šiaučiulis, Adam West, Gregory J. P. Perry, and David J. Procter* Department of Chemistry, University of Manchester, Oxford Road, Manchester, M13 9PL, UK.

*Corresponding author. david.j.procter@manchester.ac.uk.

\section{Abstract}

Aryl-aryl cross-coupling constitutes one of the most widely used procedures for the synthesis of high-value materials, ranging from pharmaceuticals to organic electronics and conducting polymers. The assembly of (hetero)biaryl scaffolds generally requires multiple steps; coupling partners must be functionalized before the key bond-forming event is considered. Thus, the development of selective $\mathrm{C}-\mathrm{H}$ arylation processes in arenes, that side-step the need for prefunctionalized partners, is crucial for streamlining the construction of these key architectures. Here we report an expedient, one-pot assembly of (hetero)biaryl motifs using photocatalysis and two non-prefunctionalized arene partners. The approach is underpinned by the functionalization of a $\mathrm{C}-\mathrm{H}$ bond in an arene coupling partner using the interrupted Pummerer reaction. A unique pairing of the organic photoredox catalyst and the intermediate dibenzothiophenium salts enables highly selective reduction in the presence of sensitive functionalities. The utility of the metal-free, one-pot strategy is exemplified by the synthesis of a bioactive natural product and the modification of complex molecules of societal importance.

\section{Introduction}

The construction of (hetero)biaryls is a key application of cross-couplings, ${ }^{1}$ as the motif is ubiquitous amongst medicines, functional materials, and agrochemicals. ${ }^{2,3}$ Although powerful, traditional cross-couplings require two prefunctionalized partners and supply-risk platinum group metals. In order to streamline synthesis, it is desirable to engage non-prefunctionalized starting materials in cross-coupling processes that selectively functionalize substrates at the expense of $\mathrm{C}-\mathrm{H}$ bonds in order to access novel building blocks or modify complex structures at a 
late-stage. Methods for accessing (hetero)biaryl motifs through selective $\mathrm{C}-\mathrm{H} / \mathrm{C}-\mathrm{H}$ couplings have grown in sophistication in recent years, ${ }^{4}$ however, methods can still require platinum group metals, high temperatures and/or suffer from the need for prefunctionalization in the form of a directing group to ensure site selective $\mathrm{C}-\mathrm{H}$ functionalization. ${ }^{5}$ The use of photoredox catalysis has emerged as a complementary approach to (hetero)biaryls that operates under mild conditions and, in some cases, without the requirement for transition metals. While initial reports used aryl diazonium salts as substrates, ${ }^{6,7}$ recent progress has allowed less hazardous and more available substrates such as aryl halides to be used (Fig. 1a). ${ }^{8-13}$ A process that allowed the one-pot coupling of two non-prefunctionalized partners using photoredox catalysis would represent a clear advance. Here we present a general and effective photoredox-catalyzed approach to achieve the chemo- and regioselective, formal $\mathrm{C}-\mathrm{H} / \mathrm{C}-$ $\mathrm{H}$ coupling of non-prefunctionalized arenes. The one-pot approach is underpinned by the selective interrupted Pummerer activation of an arene partner, using 1.1 equivalents of a benzothiophene $S$-oxide mediator activated by 1.2 equivalents of triflic anhydride, prior to catalytic cross-coupling with a second, non-prefunctionalized partner, mediated by an organic photocatalyst and visible light (Fig. 1b).

a

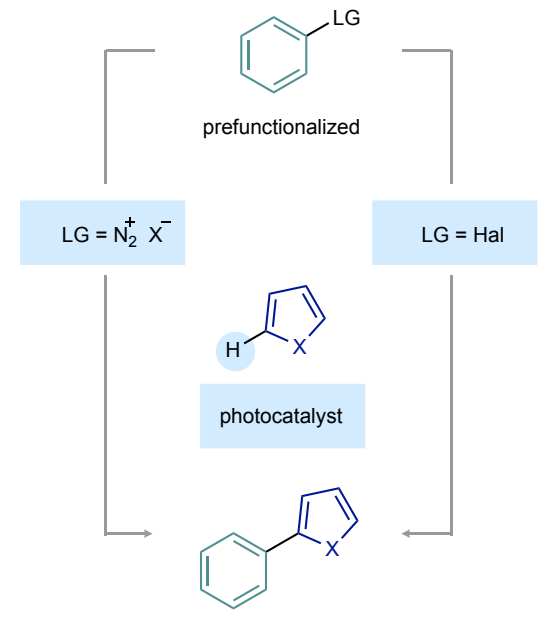

b

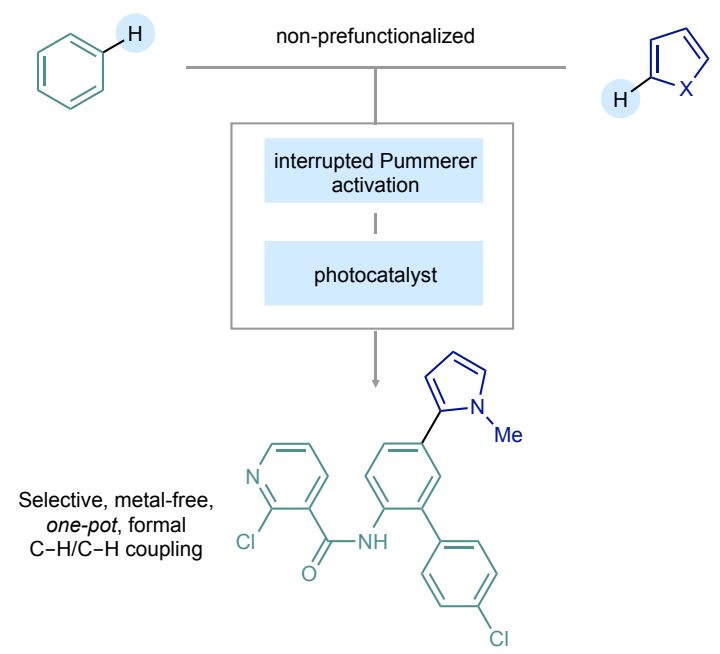

Figure 1. | Strategies for arylation of arenes. a, Photocatalytic approaches for the preparation of (hetero)biaryls. Such methods require prefunctionalized arene coupling partners, for example, aryl diazonium salts or aryl halides. b, Outline of a metal-free, strategy for the one-pot, photocatalytic, formal $\mathrm{C}-\mathrm{H} / \mathrm{C}-\mathrm{H}$ coupling of nonprefunctionalized arenes that relies on a selective, interrupted Pummerer reaction to activate one partner. LG = Leaving group. 


\section{Results}

Design of the reaction sequence Owing to their reactivity at both oxygen and at sulfur, and the tuneability of such reactivity, sulfoxides are attracting significant attention as selective activators of partners for cross-coupling, often at the expense of $\mathrm{C}-\mathrm{H}$ bonds. ${ }^{14-36}$ We recently disclosed a strategy to activate the $\mathrm{C}-\mathrm{H}$ bonds of nucleophilic alkenes using sulfoxides. ${ }^{37}$ Sulfenylation by sulfoxide results in in situ polarity reversal of nucleophilic alkenes and the resultant alkenyl sulfonium salts are willing partners in nickel-catalyzed cross-couplings with organozincs that are carried out in the same pot. Herein, we report an effective, one-pot method for the selective, formal $\mathrm{C}-\mathrm{H} / \mathrm{C}-\mathrm{H}$ cross-coupling of non-prefunctionalized arene partners through the marriage of interrupted Pummerer activation and organophotocatalysis (Fig. 2a). Exploiting commercial dibenzothiophene S-oxide (DBTSO) as the process mediator ensures high selectivity and high reactivity in both sulfenylation and aryl radical generation, and the byproduct dibenzothiophene can be easily recovered and recycled. Key to the approach is the identification of 10phenylphenothiazine (PTH) as the optimal photocatalyst (see Supplementary Table 1 for full optimization studies and comparison with more conventional photoredox catalysts). The protocol involves direct reduction of the substrate by the excited catalyst and does not require super-stoichiometric quantities of electron donors (e.g. amines) to access the reactive state of the photocatalyst and enable efficient turnover. ${ }^{38-40}$ When compared to existing photocatalyzed approaches to heterobiaryls, we avoid practical issues of safety, stability and availability associated with aryl diazonium salts, ${ }^{6,7}$ and the very negative reduction potentials of aryl halides, in particular electron-rich aryl halides. ${ }^{7-13}$ By transforming simple arenes into sulfonium salts, we gain access to a class of bench stable, aryl radical precursors, of complementary reactivity, when compared to diazonium salts and halides, for use in formal $\mathrm{C}-\mathrm{H} / \mathrm{C}-\mathrm{H}$ cross couplings.

Our blueprint for the process begins with sulfoxide activation of the nucleophilic arene, by an interrupted Pummerer reaction, to generate the corresponding aryldibenzothiophenium salt (Ar-DBT ${ }^{+} ;$Fig. 2 b, A $\rightarrow$ B). Single electron transfer (SET) from the excited state PTH to the Ar-DBT+ results in the expulsion of dibenzothiophene and concomitant formation of an aryl radical species (Fig. 2b, B $\rightarrow$ C). Sulfonium salts, ${ }^{41,42}$ in $^{\text {particular }}$ triarylsulfonium salts, ${ }^{43,33}$ have previously been investigated as aryl radical precursors using traditional ruthenium 
and iridium photocatalysts, but due to their inherent structure, they display non-selective $\mathrm{C}-\mathrm{S}$ bond cleavage and radical generation. Crucially, the choice of sulfonium salts formed from dibenzothiophene S-oxide (e.g. 2) is key as; i) SET reduction of the C-S bond is promoted by a gain in aromaticity, and; ii) SET reduction leads to selective cleavage of one of the $\mathrm{C}-\mathrm{S}$ bonds. After subsequent trapping of the aryl radical (Fig. $2 b, \mathbf{C} \rightarrow \mathbf{D}$ ), turnover of the catalytic cycle is thought to occur through oxidation of the newly formed radical adduct and aromatization delivers the product (Fig. 2b, $\mathbf{D} \rightarrow \mathbf{E} \rightarrow \mathbf{F}$ ). After optimisation (see Supplementary Tables $1,2 \& 3$ for full details), the metal-free, one-pot process was exemplified by the formal $\mathrm{C}-\mathrm{H} / \mathrm{C}-\mathrm{H}$ coupling of tert-butylbenzene 1 and $\mathrm{N}$ methyl pyrrole to give (hetero)biaryl 3 (Fig. 2c).

a
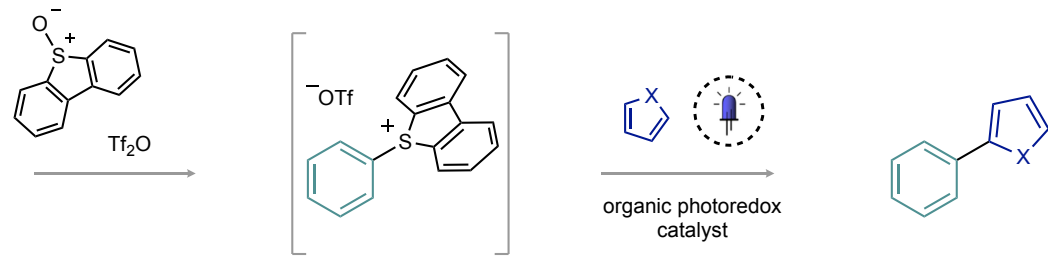

b
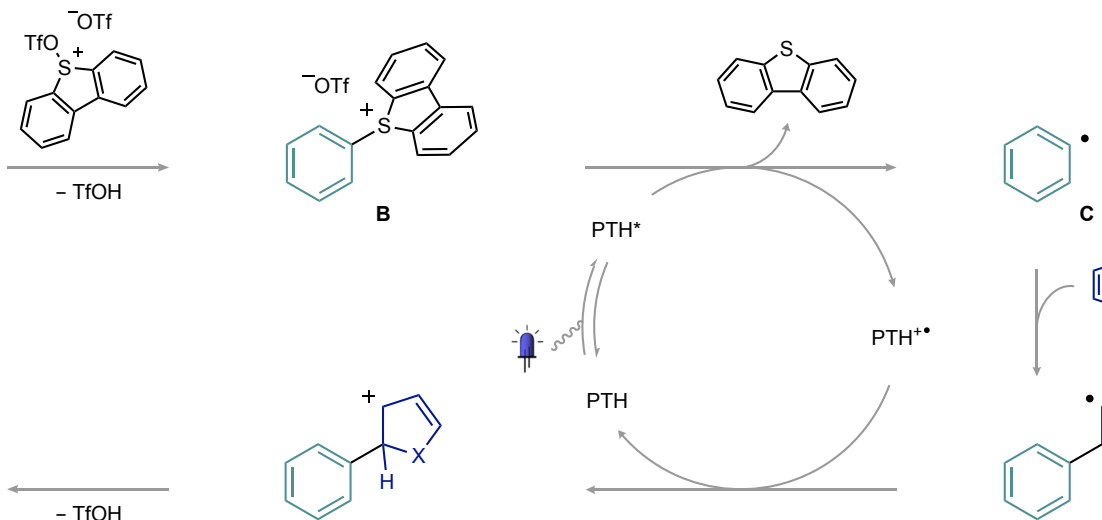

B<smiles>Fc1cccc(-c2ccccc2)c1</smiles><smiles>[C]1C=C[CH+]C1c1ccccc1</smiles>

$\mathrm{E}$

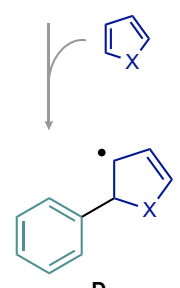

c
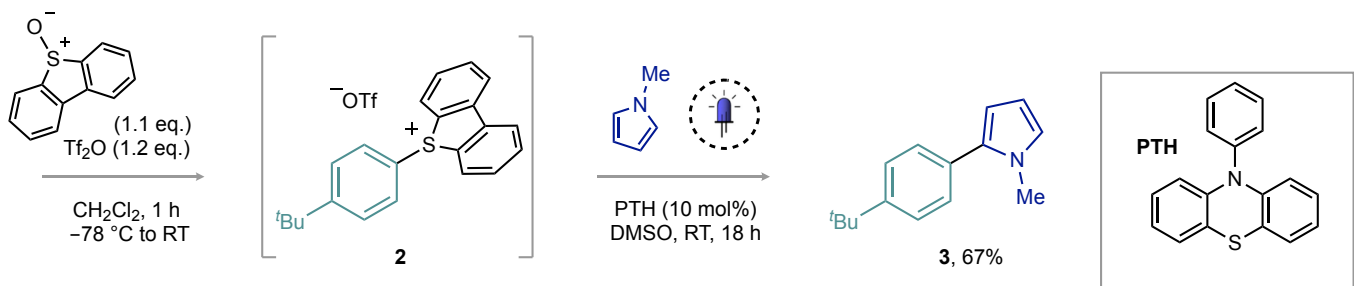

Figure 2. | Mechanistic proposal for a one-pot, metal-free, photoredox-catalyzed $\mathrm{C}-\mathrm{H} / \mathrm{C}-\mathrm{H}$ coupling of arenes, enabled by the interrupted Pummerer activation. a, Overview of the developed sequence. b, Mechanistic proposal: interrupted Pummerer activation of arene A generates the corresponding $\mathrm{Ar}-\mathrm{DBT}^{+}$salt $\mathbf{B}$. Single electron reduction of $\mathbf{B}$ releases aryl radical $\mathbf{C}$, which is coupled with the arene trap to form $\mathbf{D}$. Single electron 
oxidation of $\mathbf{D}$ closes the catalytic cycle and delivers the product of aryl-aryl coupling F. $\mathbf{c}$, Exemplification of a one-pot, metal-free, photoredox-catalyzed $\mathrm{C}-\mathrm{H} / \mathrm{C}-\mathrm{H}$ coupling of arenes, enabled by interrupted Pummereractivation, using tert-butylbenzene and $\mathrm{N}$-methylpyrrole. PTH, 10-phenylphenothiazine.

Mechanistic investigations To gain support for the proposed reaction mechanism, the feasibility of the SET event was assessed using cyclic voltammetry (CV). CV analysis of a range of dibenzothiophenium salts, showed irreversible reduction profiles with $E^{\text {red }}=-1.1 \mathrm{~V}$ (versus saturated calomel electrode, SCE) in DMSO (Supplementary Fig. 1, 2, and 3), significantly less negative than that determined for the excited state of PTH $\left(\mathrm{E}_{1 / 2}^{\mathrm{red}}{ }^{*}=-2.1 \mathrm{~V}\right.$ versus SCE; Supplementary Fig. 5) in DMSO. In line with these findings, Stern-Volmer experiments confirmed that $\mathrm{Ar}-\mathrm{DBT}^{+}$salt $\mathbf{2}$ effectively quenches the excited state of the photocatalyst (Fig. 3a and Supplementary Fig. 9 and 11). Radical scavenger and radical probe experiments were also used to probe the reaction mechanism. The presence of 2,2,6,6-tetramethylpiperidin-1-yl)oxyl (TEMPO) in the reaction mixture inhibited the formation of (hetero)biaryl 3 (Fig. 3b) while the addition of radical scavenger 1,1-diphenylethylene $(\mathrm{DPE})^{11,44}$ gave the product of radical trapping 4 (Fig. 3c). Finally, reduction of engineered $\mathrm{Ar}-\mathrm{DBT}^{+}$salt $\mathbf{5}$, containing an ortho-allyl ether moiety, gave additional support for the proposed mechanism; 5-exo-trig radical cyclization/addition product 6 was obtained in low isolated yield (Fig. 3d). Measurement of the quantum yield of the reaction to form $3(0.18)$ supports the proposed closed cycle and appears to rule out a radical chain process in which $\mathbf{D}$ reduces $\mathbf{B}$, to generate $\mathbf{C}$ and $\mathbf{E} .{ }^{40}$ 
a

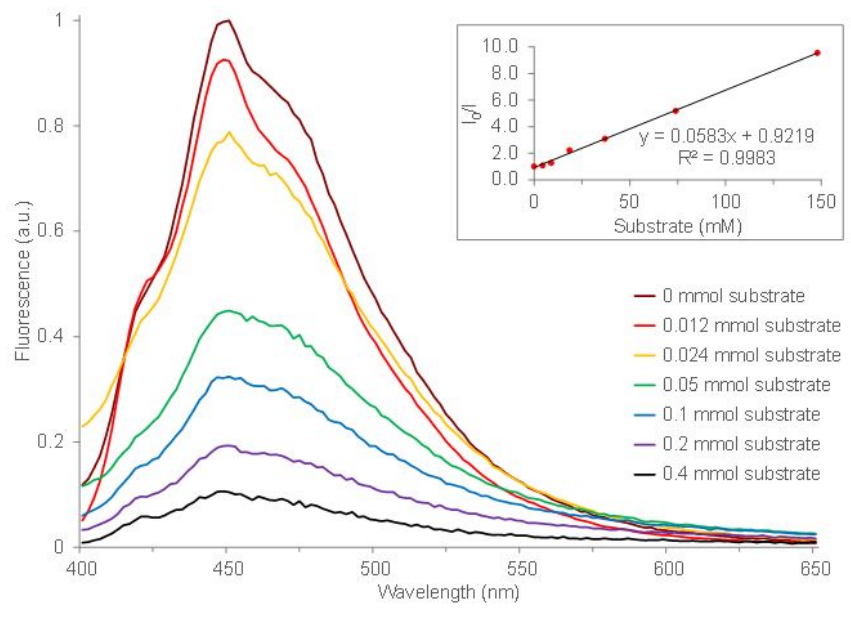

b

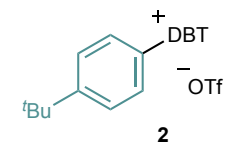

c

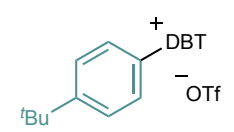

2

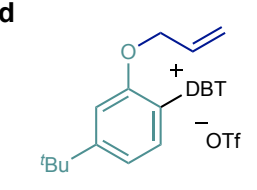

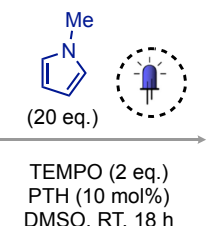
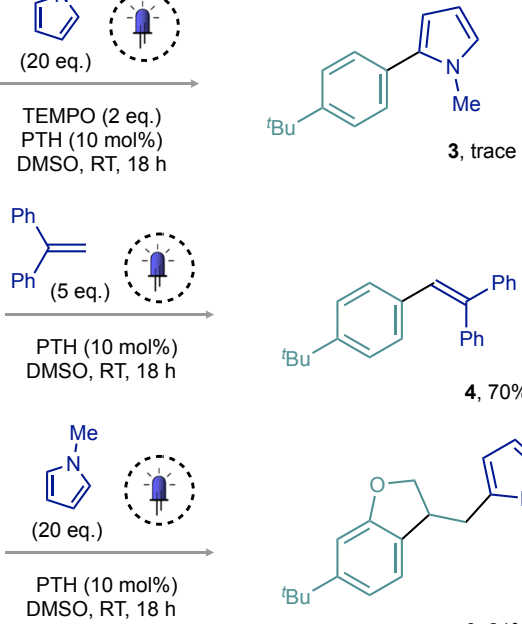

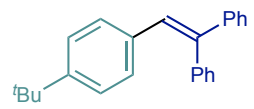

$4,70 \%$

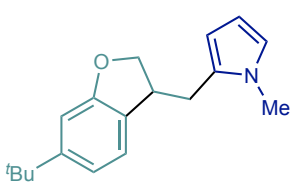

6, $21 \%$

Figure 3. | Mechanistic investigations. a, Fluorescence studies show the quenching of PTH upon addition of Ar$\mathrm{DBT}^{+}$salt 2. $\mathbf{b}$, The presence of TEMPO inhibits the photoredox $\mathrm{C}-\mathrm{H} / \mathrm{C}-\mathrm{H}$ coupling. $\mathbf{c}$, the postulated aryl radical intermediate can be intercepted by the radical trap 1,1-diphenylethene to afford alkenylated product 4 . $\mathbf{d}$, An intramolecular radical trap experiment using the allyl ether-containing substrate $\mathbf{5}$ delivers the product or radical cyclization/addition 6. $\mathrm{DBT}^{+}$, dibenzothiophenium; TEMPO, 2,2,6,6-tetramethylpiperidin-1-yl)oxyl.

Evaluation of the protocol's substrate scope Having established optimal reaction conditions and gained support support for our mechanistic proposal, we set about determining the generality of the one-pot, formal $\mathrm{C}-\mathrm{H} / \mathrm{C}-\mathrm{H}$ coupling (Table 1). Simple, alkyl-substituted arenes were arylated with $N$-methylpyrrole in good overall yields (3 and 7-10). More electron-rich phenol and aniline derivatives also underwent coupling in good yields over the two stages of the process (11-17). To assess the compatibility of various functional groups, a range of substituted anisoles were then engaged in the arylation sequence. Substrates bearing halogens, triflyl, mesyl, keto, amido, ester, trifluromethyl, and cyano groups all provided the desired heterobiaryls with complete chemoselectivity (1828). The high chemoselectivity observed in the reduction of the $\mathrm{Ar}-\mathrm{DBT}^{+}$group is particularly noteworthy, given that PTH has previously been shown to catalyse the reduction of aryl halides ${ }^{45-48}$ and trifluoromethyl groups. ${ }^{49}$ The process' tolerance of halide and triflyl functional groups signals its orthogonality with regard to traditional crosscoupling and ensures that further structural modification of products can be carried out using conventional cross- 
coupling processes. Furthermore, performing the preparation of $\mathbf{2 6}$ on a $10 \mathrm{mmol}$ scale, without any alterations to the reaction conditions or set-up, revealed that the protocol is scalable. By-products resulting from reduction of the aryl radical intermediate or homocoupling of the arylsulfonium salts are not observed. The presence of hydroxyl and amino groups ${ }^{50}$ is currently problematic; for example, while 4-tert-butylphenol undergoes sulfenylation, cross-coupling of the resultant salt gave only a trace of product (29). However, limited success in activating and coupling another phenol substrate has been achieved (see Supplementary Methods, synthesis of S12 \& S13). We next turned our attention to the one-pot coupling of electron-rich heteroaromatic substrates. While thiophene substrates showed some compatibility (31-33), furan and pyrrole were too reactive (34, 35). 


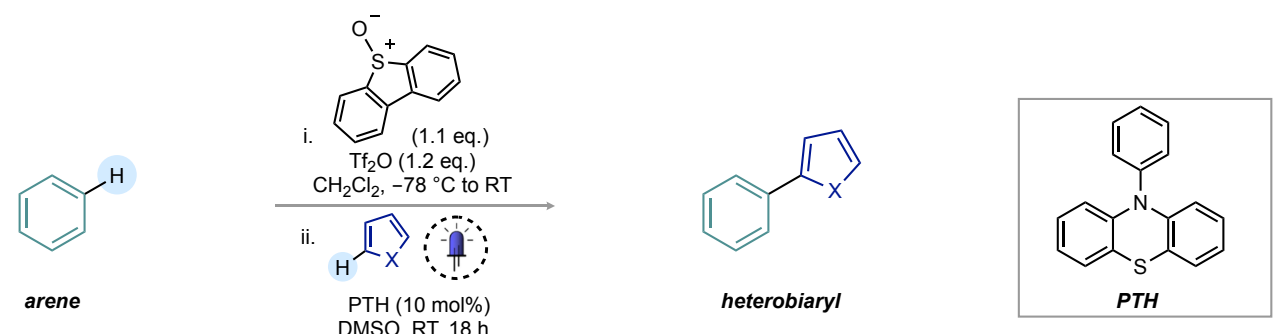

a Arenes
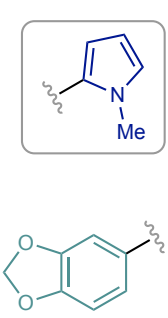

$11,62 \%$

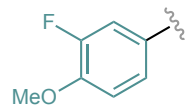

18. $67 \%$

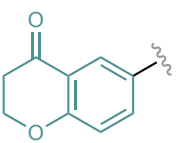

$24,48 \%$

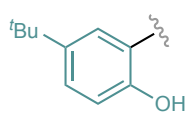

29, - ${ }^{\mathrm{c}}$

b Radical Traps
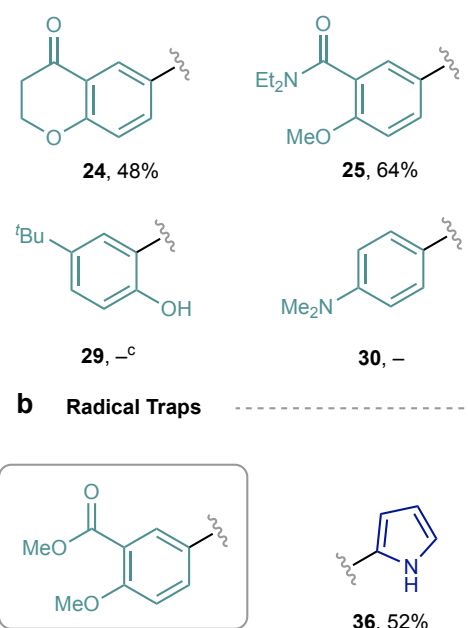

25, $64 \%$

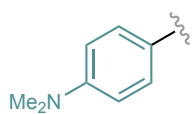

30, -
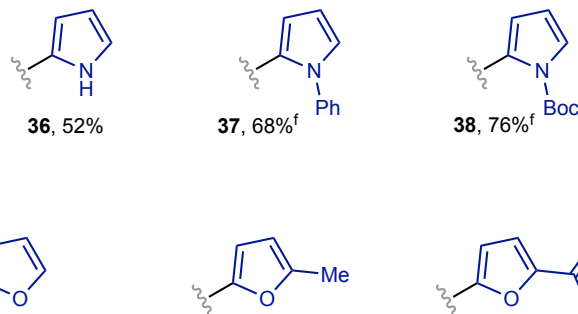

44, $53 \%$

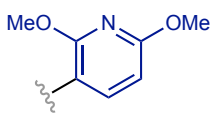

51, $42 \%$

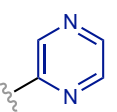

50, $42 \%$

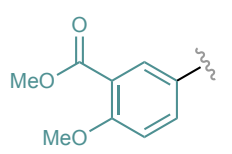

26, $67 \%$

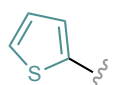

31, $51 \%$

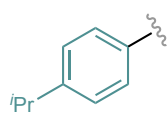

9, $49 \%$

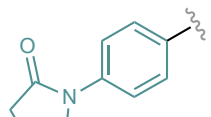

$14,60 \%$
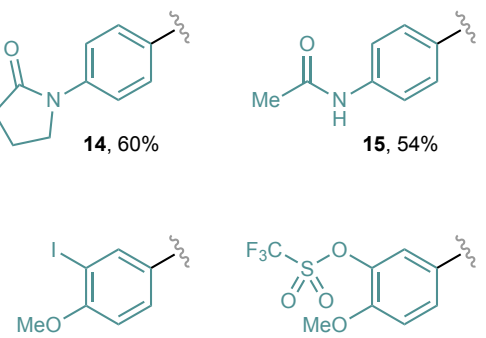

21, $64 \%$

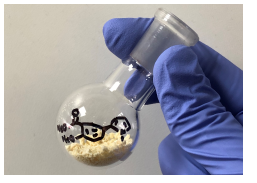

26, $59 \%(68 \%)^{b}$ $10 \mathrm{mmol}$ scale

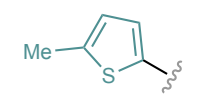

$32,66 \%^{\mathrm{d}}$
$15,54 \%$

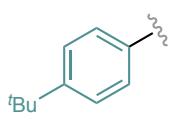

3, $51 \%$
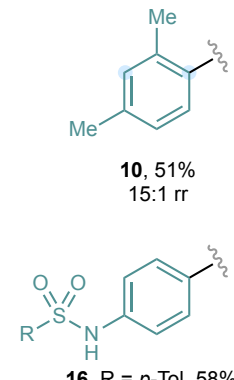

$16, \mathrm{R}=p$-Tol, $58 \%$

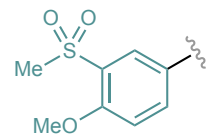

23, $76 \%$

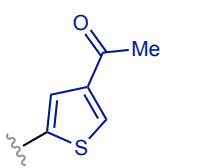

42, $65 \%$

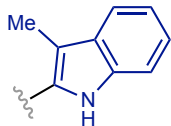

49, $52 \%$

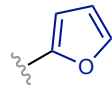

43, $57 \%$

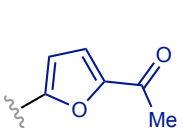

45, $70 \%$<smiles>Cc1ccccc1</smiles>

52, $55 \%^{a}$<smiles></smiles><smiles>[Te]c1cccs1</smiles>

40, $59 \%$

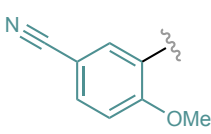

28, $71 \%$

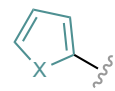
34, $\mathrm{X}=\mathrm{O},-$
$35, \mathrm{X}=\mathrm{NH}$,

Table 1. | Evaluation of the substrate scope in the metal-free, photoredox-catalyzed, formal C-H/C-H coupling of arenes, enabled by interrupted Pummerer activation. a, Substrate scope with respect to the arene coupling 
partner. $\mathbf{b}$, Substrate scope with respect to the (hetero)arene radical trap. All reactions were run on $0.2 \mathrm{mmol}$ scale with 20 equivalents of the trapping reagent, unless stated otherwise. ${ }^{\mathrm{a}} 1 \mathrm{~mL}$ of radical trap used. ${ }^{\mathrm{b}}$ based on recovered starting material. ${ }^{\text {T }}$ The intermediate sulfonium salt could be prepared in $51 \%$ yield in acetonitrile. dtrifluoroacetic anhydride (1.2 eq.) used instead of triflic anhydride. ${ }^{\mathrm{e}}$ Yield determined by $1 \mathrm{H}-\mathrm{NMR}$ analysis of crude reaction mixture. ${ }^{f} 10$ equivalents of radical trap used.

We next evaluated the scope with respect to the trapping (hetero)arene. A range of substituted pyrroles (36-39), thiophenes (40-42), furans (43-47), benzofuran (48), and indole (49) partners was used successfully in the coupling. In the cases of 3-substituted heterocycles, complete regiocontrol was observed (42, 46, and 47). Ar$\mathrm{DBT}^{+}$salts can also engage in Minisci-type couplings (50). Finally, in addition to being capable of activation using the interrupted Pummerer process, arenes can also serve as radical trapping agents, thus allowing access to biaryls (52-55).

Application of the developed sequence To showcase the potential of the one-pot, metal-free strategy, we have applied it to the synthesis and modification of several complex molecules. We first targeted the pseudilin marine natural products (Fig. 4a). Owing to their unusual, highly halogenated structures, pseudilins have gained attention in recent years and have been found to exhibit antibiotic, antitumor, and phytotoxic activities. ${ }^{51-53}$ Previous routes to the pseudilins have invariably used stepwise heterocycle construction from precursor benzaldehydes or phenyl ketones, with the shortest synthesis to date being seven steps in length. ${ }^{53}$ Engaging commercial 2,4dichloroanisole in our one-pot sequence delivered $\mathrm{N}$-H heterobiaryl $\mathbf{5 6}$ after removal of the tert-butoxycarbonyl group. (2,4-Dichlorophenol underwent sulfenylation and cross-coupling in significantly lower overall yield). Subsequent chlorination and demethylation provided natural, pentachloropseudilin $\mathbf{5 7}$, while bromination of the pyrrole ring enabled access to the dichloro-tribromopseudilin analogue $\mathbf{5 8}$, both in good overall yield. 
Our method is also suited to the selective modification of complex scaffolds of biological significance (Fig. 4b). Salicin pentaacetate (52), boscalid (53), fenofibrate (54), clofibrate (55), and $N$-acetylmexiletine (56) underwent smooth arylation using the two-stage, one-pot process. Complete chemo- and regiocontrol was observed in all cases. The structure of $\mathbf{5 3}$ was confirmed by X-ray crystallographic analysis.

a

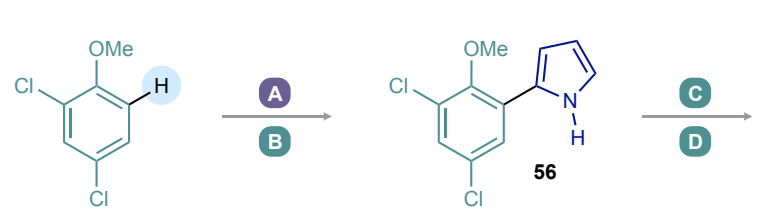

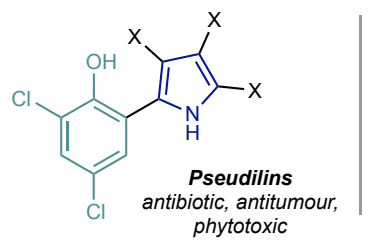

phytotoxic A Interrupted Pummerer-enabled,
metal-free, photoredox arylation

B Boc removal

C Halogenation

D Demethylation

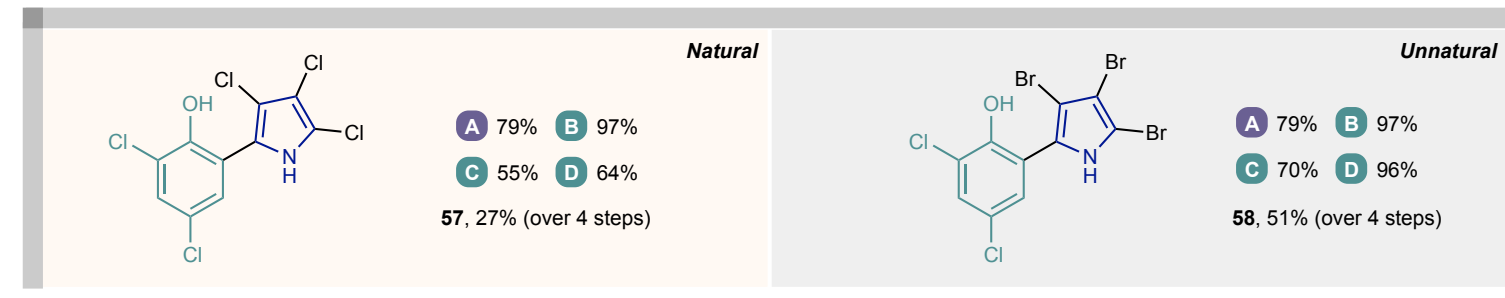

b
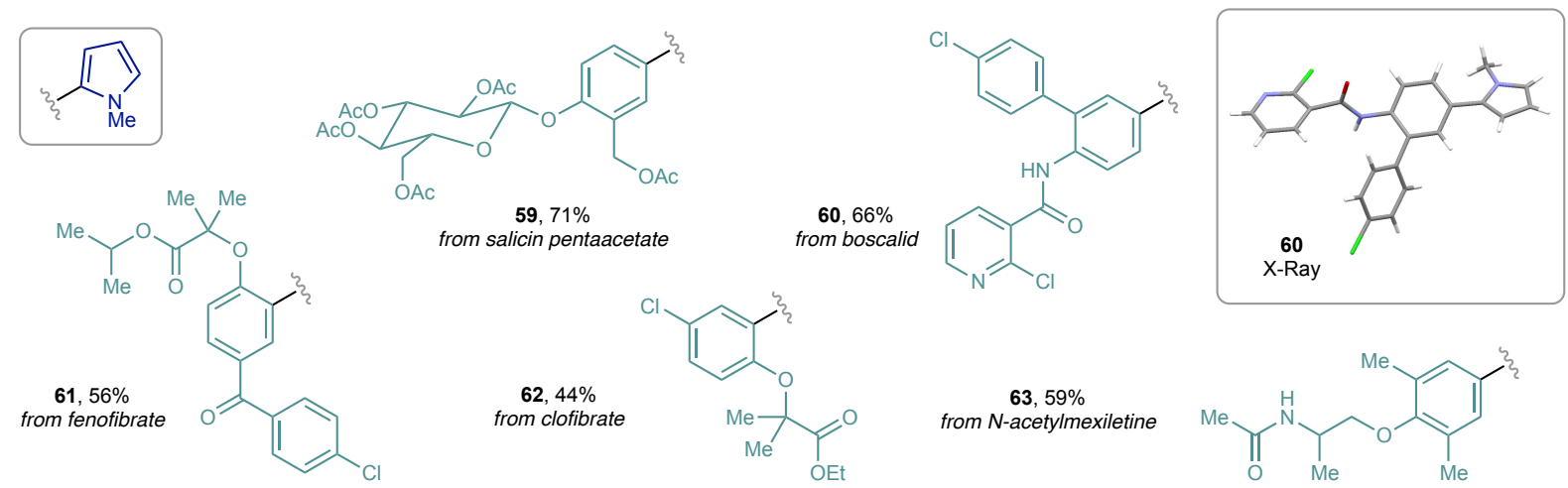

Figure 4. | Application of the one-pot, metal-free photoredox-catalyzed, formal $\mathrm{C}-\mathrm{H} / \mathrm{C}-\mathrm{H}$ coupling of arenes,

enabled by interrupted Pummerer activation. a, Concise synthesis of a bioactive Pseudilin natural product and an analogue. Reaction conditions: A, arene (1.0 equiv.), DBTSO (2.0 equiv.), triflic anhydride (2.0 equiv.), $\mathrm{CH}_{2} \mathrm{Cl}_{2}(0.1$ M), $-78^{\circ} \mathrm{C}$ to $-40{ }^{\circ} \mathrm{C}, 2$ hour, then PTH (10 mol\%), $N$-Boc pyrrole (10 equiv.), DMSO (0.2 M), blue LED irradiation, 18 hours. B, Sodium methoxide ( $30 \% \mathrm{w} / \mathrm{w}$ in $\mathrm{MeOH}, 10$ equiv.), THF $(0.14 \mathrm{M}), 45^{\circ} \mathrm{C}, 2$ hours. $\mathrm{C}$, chlorination: NCS (3.0 equiv.), MeCN (0.05 M), $-40{ }^{\circ} \mathrm{C}$ to RT, 15 hours. bromination: Pyridinium tribromide (3.0 equiv.), EtOH (0.06 M), RT, 30 minutes. D, Boron tribromide (1.1 equiv.), $\mathrm{CH}_{2} \mathrm{Cl}_{2}(0.04 \mathrm{M}),-78{ }^{\circ} \mathrm{C}$ to $0{ }^{\circ} \mathrm{C}, 2$ hours. $\mathbf{b}$, Late-stage 
functionalization of bioactive molecules. Reaction conditions: arene (1.0 equiv.), DBTSO (1.1 equiv.), triflic anhydride (1.2 equiv.), $\mathrm{CH} 2 \mathrm{Cl} 2(0.1 \mathrm{M}),-78{ }^{\circ} \mathrm{C}$ to RT, 2 hour, then PTH (10 mol\%), $N$-Methyl pyrrole (20 equiv.), DMSO (0.2 M), blue LED irradiation, 18 hours.

\section{Conclusions}

We have developed a one-pot strategy for the rapid construction of (hetero)biaryl motifs from nonprefunctionalized partners using a combination of organophotocatalysis and substrate activation using the interrupted Pummerer reaction. Our formal $\mathrm{C}-\mathrm{H} / \mathrm{C}-\mathrm{H}$ cross-coupling allows (hetero)biaryl carbon frameworks to be assembled under metal-free conditions, without multi-step synthesis. The marriage of the organic photoredox catalyst, 10-phenylphenothiazine, and intermediate aryldibenzothiophenium salts is unique and has led to a highly selective process that is broad in scope. The utility of the strategy has been exemplified by the synthesis of the bioactive natural product pentachloropseudilin and the modification of complex molecules of societal importance.

\section{Methods}

General Procedure for the formal $\mathrm{C}-\mathrm{H} / \mathrm{C}-\mathrm{H}$ coupling of arenes $\mathrm{Tf}_{2} \mathrm{O}$ (1.2 equiv.) was slowly added to a stirred solution of the arene $\left(0.2 \mathrm{mmol}, 1.0\right.$ equiv.) and dibenzothiophene $S$-oxide (1.1 equiv.) in $\mathrm{CH}_{2} \mathrm{Cl}_{2}(0.1 \mathrm{M})$ at $-78^{\circ} \mathrm{C}$ under a nitrogen atmosphere. The resulting solution was stirred at this temperature for 15 minutes before warming to room temperature. After stirring for $1 \mathrm{~h}$, TLC analysis showed complete consumption of the arene starting material, at which point the solvent was removed in vacuo. 10-Phenyl-phenothiazine (10 mol\%) was then added to the reaction vial, followed by evacuation and refilling with nitrogen ( 3 cycles). DMSO $(0.2 \mathrm{M})$ was then added followed by the radical trap reagent. The reaction mixture was then irradiated with a Kessil $34 \mathrm{~W}$ blue LED lamp for $18 \mathrm{~h}$ before quenching with aqueous saturated $\mathrm{NaHCO}_{3}$ and dilution with EtOAc. The organic layer was 
washed with brine, dried using $\mathrm{MgSO}_{4}$, filtered, and concentrated in vacuo, to give the crude product, which was purified by column chromatography on silica gel.

\section{Data Availability}

All data is available in the main text or the Supplementary Information. Metrical parameters for the structures of $\mathbf{2}$ and $\mathbf{5 3}$ (see Supplementary Information) are available free of charge from the Cambridge Crystallographic Data Centre (https://www.ccdc.cam.ac.uk/) under reference numbers CCDC 1922367 and 1922368.

\section{References}

1 Johansson Seechurn, C. C. C., Kitching, M. O., Colacot, T. J. \& Snieckus, V. Palladium-Catalyzed CrossCoupling: A Historical Contextual Perspective to the 2010 Nobel Prize. Angew. Chem. Int. Ed. 51, 50625085 (2012).

2 Roughley, S. D. \& Jordan, A. M. The Medicinal Chemist's Toolbox: An Analysis of Reactions Used in the Pursuit of Drug Candidates. J. Med. Chem. 54, 3451-3479 (2011).

3 Brown, D. G. \& Boström, J. Analysis of Past and Present Synthetic Methodologies on Medicinal Chemistry:

4 Yang, Y., Lan, J. \& You, J. Oxidative C-H/C-H Coupling Reactions between Two (Hetero)arenes. Chem. Rev. 117, 8787-8863 (2017).

5 Sambiagio, C., Schonbauer, D., Blieck, R., Dao-Huy, T., Pototschnig, G., Schaaf, P., Wiesinger, T., Zia, M. F., Wencel-Delord, J., Besset, T., Maes, B. U. W. \& Schnurch, M. A comprehensive overview of directing groups applied in metal-catalysed C-H functionalisation chemistry. Chem. Soc. Rev. 47, 6603-6743 (2018).

6 Hari, D. P., Schroll, P. \& Konig, B. Metal-Free, Visible-Light-Mediated Direct C-H Arylation of Heteroarenes with Aryl Diazonium Salts. J. Am. Chem. Soc. 134, 2958-2961 (2012).

7 Ghosh, I., Marzo, L., Das, A., Shaikh, R. \& König, B. Visible Light Mediated Photoredox Catalytic Arylation Reactions. Acc. Chem. Res. 49, 1566-1577 (2016). 
8 Nguyen, J. D., D’Amato, E. M., Narayanam, J. M. R. \& Stephenson, C. R. J. Engaging unactivated alkyl, alkenyl and aryl iodides in visible-light-mediated free radical reactions. Nat. Chem. 4, 854-859 (2012).

9 Kim, H. \& Lee, C. Visible-Light-Induced Photocatalytic Reductive Transformations of Organohalides. Angew. Chem. Int. Ed. 51, 12303-12306 (2012).

10 Ghosh, I., Ghosh, T., Bardagi, J. I. \& König, B. Reduction of aryl halides by consecutive visible light-induced electron transfer processes. Science 346, 725-728 (2014).

11 Marzo, L., Ghosh, I., Esteban, F. \& König, B. Metal-Free Photocatalyzed Cross Coupling of Bromoheteroarenes with Pyrroles. ACS Catal. 6, 6780-6784 (2016).

12 Ghosh, I. \& König, B. Chromoselective Photocatalysis: Controlled Bond Activation through Light-Color Regulation of Redox Potentials. Angew. Chem. Int. Ed. 55, 7676-7679 (2016).

13 Ghosh, I., Shaikh, R. S. \& König, B. Sensitization-Initiated Electron Transfer for Photoredox Catalysis. Angew. Chem. Int. Ed. 56, 8544-8549 (2017).

14 Smith, L. H. S., Coote, S. C., Sneddon, H. F. \& Procter, D. J. Beyond the Pummerer Reaction: Recent Developments in Thionium Ion Chemistry. Angew. Chem. Int. Ed. 49, 5832-5844 (2010).

15 Eberhart, A. J., Imbriglio, J. E. \& Procter, D. J. Nucleophilic Ortho Allylation of Aryl and Heteroaryl Sulfoxides. Org. Lett. 13, 5882-5885 (2011).

16 Huang, X. \& Maulide, N. Sulfoxide-Mediated $\alpha$-Arylation of Carbonyl Compounds. J. Am. Chem. Soc. 133, 8510-8513 (2011).

17 Eberhart, A. J. \& Procter, D. J. Nucleophilic ortho-Propargylation of Aryl Sulfoxides: An Interrupted Pummerer/Allenyl Thio-Claisen Rearrangement Sequence. Angew. Chem. Int. Ed. 52, 4008-4011 (2013).

18 Huang, X., Patil, M., Fares, C., Thiel, W. \& Maulide, N. Sulfur(IV)-Mediated Transformations: From Ylide Transfer to Metal Free Arylation of Carbonyl Compounds. J. Am. Chem. Soc. 135, 7312-7323 (2013).

19 Peng, B., Huang, X., Xie, L-G. \& Maulide, N. A Brønsted Acid Catalyzed Redox Arylation. Angew. Chem. Int. Ed. 53, 8718-8721 (2014).

20 Peng, B., Geerdink, D., Fars, C. \& Maulide, N. Chemoselective Intermolecular $\alpha$-Arylation of Amides. Angew. Chem. Int. Ed. 53, 5462-5466 (2014). 
21 Pulis, A. P. \& Procter, D. J. C-H Coupling Reactions Directed by Sulfoxides: Teaching an Old Functional Group New Tricks. Angew. Chem. Int. Ed. 55, 9842-9860 (2016).

22 Fernandez-Salas, J. A., Eberhart, A. J. \& Procter, D. J. Metal-Free CH-CH-Type Cross-Coupling of Arenes and Alkynes Directed by a Multifunctional Sulfoxide Group. J. Am. Chem. Soc. 138, 790-793 (2016).

23 Cowper, P., Jin, Y., Turton, M. D., Kociok-Köhn, G. \& Lewis, S. E. Azulenesulfonium Salts: Accessible, Stable, and Versatile Reagents for Cross-Coupling. Angew. Chem. Int. Ed. 55, 2564-2568 (2016).

24 Li, Y., Qiu, D., Gu, R., Wang, J., Shi, J. \& Li, Y. Aryne 1,2,3-Trifunctionalization with Aryl Allyl Sulfoxides. J. Am. Chem. Soc. 138, 10814-10817 (2016).

25 Yanagi, T., Otsuka, S., Kasuga, Y., Fujimoto, K., Murakami, K., Nogi, K., Yorimitsu, H. \& Osuka, A. MetalFree Approach to Biaryls from Phenols and Aryl Sulfoxides by Temporarily Sulfur-Tethered Regioselective C-H/C-H Coupling. J. Am. Chem. Soc. 138, 14582-14585 (2016).

26 Shrives, H. J., Fernandez-Salas, J. A., Hedtke, C., Pulis, A. P. \& Procter, D. J. Regioselective synthesis of C3 alkylated and arylated benzothiophenes. Nat. Commun. 8, 14801 (2017).

27 Kaldre, D., Maryasin, B., Kaiser, D., Gajsek, O., Gonzalez, L. \& Maulide, N. An Asymmetric Redox Arylation: Chirality Transfer from Sulfur to Carbon through a Sulfonium [3,3]-Sigmatropic Rearrangement. Angew. Chem. Int. Ed. 56, 2212-2215 (2017).

28 Chen, D., Feng, Q., Yang, Y., Cai, X-M., Wang F. \& Huang, S. Metal-free O-H/C-H difunctionalization of phenols by o-hydroxyarylsulfonium salts in water. Chem. Sci. 8, 1601-1606 (2017).

29 Yorimitsu, H. Cascades of Interrupted Pummerer Reaction-Sigmatropic Rearrangement. Chem. Rec. 17, 1156-1167 (2017).

30 Shang, L., Chang, Y., Luo, F., He, J-N., Huang, X., Zhang, L., Kong, L., Li, K. \& Peng, B. Redox-Neutral $\alpha-$ Arylation of Alkyl Nitriles with Aryl Sulfoxides: A Rapid Electrophilic Rearrangement. J. Am. Chem. Soc. 139, 4211-4217 (2017).

31 He, Z., Shrives, H. J., Fernandez-Salas, J. A., Abengozar, A., Neufeld, J., Yang, K., Pulis, A. P. \& Procter, D. J. Synthesis of C2 Substituted Benzothiophenes via an Interrupted Pummerer/[3,3]-Sigmatropic/1,2Migration Cascade of Benzothiophene S-Oxides. Angew. Chem. Int. Ed. 57, 5759-5764 (2018). 
32 Zhang, L., He, J-N., Liang, Y., Hu, M., Shang, L., Huang, X., Kong, L., Wang, Z-X. \& Peng, B. Selective [5,5]Sigmatropic Rearrangement by Assembly of Aryl Sulfoxides with Allyl Nitriles. Angew. Chem. Int. Ed. 58, 5316-5320 (2019).

33 Berger, F., Plutschack, M. B., Riegger, J., Yu, W., Speicher, S., Ho, M., Frank, N. \& Ritter, T. Site-selective and versatile aromatic C-H functionalization by thianthrenation. Nature 567, 223-228 (2019).

$34 \mathrm{He}$, Z., Pulis, A. P. \& Procter, D. J. The Interrupted Pummerer Reaction in a Sulfoxide-Catalyzed Oxidative Coupling of 2-Naphthols. Angew. Chem. Int. Ed. 58, 7813-7817 (2019).

35 He, Z., Pulis, A. P., Perry, G. J. \& Procter, D. J. Pummerer chemistry of benzothiophene S-oxides: Metalfree alkylation and arylation of benzothiophenes, Phosphorus, Sulfur, and Silicon and the Related Elements (2019) DOI: 10.1080/10426507.2019.1602626

36 Šiaučiulis, M., Ahlsten, N., Pulis, A. P. \& Procter, D. J. Transition-Metal-Free Cross-Coupling of Benzothiophenes and Styrenes in a Stereoselective Synthesis of Substituted (E,Z)-1,3-Dienes. Angew. Chem. Int. Ed. 58, 8779-8783 (2019).

37 Aukland, M. H., Talbot, F. J. T., Fernandez-Salas, J. A., Ball, M., Pulis, A. P. \& Procter, D. J. An Interrupted Pummerer/Nickel-Catalysed Cross-Coupling Sequence. Angew. Chem. Int. Ed. 57, 9785-9789 (2018).

38 Prier, C. K., Rankic, D. A. \& MacMillan, D. W. C. Visible Light Photoredox Catalysis with Transition Metal Complexes: Applications in Organic Synthesis. Chem. Rev. 113, 5322-5363 (2013).

39 Romero, N. A. \& Nicewicz, D. A. Organic Photoredox Catalysis. Chem. Rev. 116, 10075-10166 (2016).

40 Cismesia, M. A. \& Yoon, T. P. Characterizing chain processes in visible light photoredox catalysis. Chem. Sci. 6, 5426-5434 (2015).

41 Hedstrand, D. M., Kruizunga, W. H. \& Kellogg, R. M. Light induced and dye accelerated reductions of phenacyl onium salts by 1,4-dihydropyridines. Tetrahedron Lett. 14, 1255-1258 (1978).

42 Otsuka, S., Nogi, K., Rovis, T. \& Yorimitsu, H. Photoredox-Catalyzed Alkenylation of Benzylsulfonium Salts. Chem. Asian J. 14, 532-536 (2019).

43 Donck, S., Baroudi, A., Fensterbank, L., Goddard, J-P. \& Ollivier, C. Visible-Light Photocatalytic Reduction of Sulfonium Salts as a Source of Aryl Radicals. Adv. Synth. Catal. 355, 1477-1482 (2013). 
44 Liu, W., Cao, H., Zhang, H., Zhang, H., Chung, K. H., He, C., Wang, H., Kwong, F. Y. \& Lei, A. Organocatalysis in Cross-Coupling: DMEDA-Catalyzed Direct C-H Arylation of Unactivated Benzene. J. Am. Chem. Soc. 132, 16737-16740 (2010).

45 Discekici, E. H., Treat, N. J., Poelma, S. O., Mattson, K. M., Hudson, Z. M., Luo, Y., Hawker, C. J. \& De Alaniz, J. R. A highly reducing metal-free photoredox catalyst: design and application in radical dehalogenations. Chem. Commun. 51, 11705-11708 (2015).

46 Garrido-Castro, A. F., Salaverri, N., Maestro, M. C. \& Aleman, J. Intramolecular Homolytic Substitution Enabled by Photoredox Catalysis: Sulfur, Phosphorus, and Silicon Heterocycle Synthesis from Aryl Halides. Org. Lett. 21, 5295-3000 (2019).

47 Boyington, A. J., Seath, C. P., Zearfoss, A. M., Xu, Z. \& Jui, N. T. Catalytic Strategy for Regioselective Arylethylamine Synthesis. J. Am. Chem. Soc. 141, 4147-4153 (2019). Martinez-Gualda, A. M., Cano, R., Marzo, L., Perez-Ruiz, R., Luis-Barrera, J., Mas-Balleste, R., Fraile, A., de la Pena O'Shea, V. A. \& Aleman, J. Chromoselective access to Z- or E- allylated amines and heterocycles by a photocatalytic allylation reaction. Nature Communications, 10, 2634 (2019).

49 Wang, H. \& Jui, N. T. Catalytic Defluoroalkylation of Trifluoromethylaromatics with Unactivated Alkenes. J. Am. Chem. Soc. 140, 163-166 (2018).

50 Yanagi, T.; Nogi, K. \& Yorimitsu, H. Construction of Biaryls from Aryl Sulfoxides and Anilines by Means of a Sigmatropic Rearrangement. Chem. -Eur. J. 25, DOI: 10.1002/chem.201903570 (2019).

51 Kunfermann, A., Witschel, M., Illarionov, B., Martin, R., Rottmann, M., Höffken, H. W., Seet, M., Eisenreich, W., Knölker, H-J., Fischer, M., Bacher, A., Groll, M. \& Diederich, F. Pseudilins: Halogenated, Allosteric Inhibitors of the Non-Mevalonate Pathway Enzyme IspD. Angew. Chem. Int. Ed. 53, 2235-2239 (2014).

52 Preller, M., Chinthalapudi, K., Martin, R., Knölker, H-J. \& Manstein, D. J. Inhibition of Myosin ATPase Activity by Halogenated Pseudilins: A Structure - Activity Study. J. Med. Chem. 54, 3675-3685 (2011). 
53 Martin, R., Jager, A., Böhl, M., Richter, S., Fedorov, R., Manstein, D. J., Gutzeit, H. O. \& Knölker, H-J. Total Synthesis of Pentabromo- and Pentachloropseudilin, and Synthetic Analogues-Allosteric Inhibitors of Myosin ATPase. Angew. Chem. Int. Ed. 48, 8042-8046 (2009).

Supplementary Information is available in the online version of the paper.

Acknowledgements We thank the EPSRC (Doctoral Prize Fellowship to M.H.A.; Established Career Fellowship to D.J.P.) and The University of Manchester (Lectureship to G.J.P.P.; Studentship to M.Š.) for their generous support. Additional thanks go to $\mathrm{Dr}$ Louise Natrajan and Dr Fabio Julia Hernandez for their assistance with the fluorescence quenching, electrochemical studies, and quantum yield determination, and to Dr Daniele Leonori for his advice on the design of experiments.

Author Contributions M.H.A. and D.J.P. conceived the study and co-wrote the manuscript. M.H.A. designed and performed experiments and M.S., A.W. and G.J.P.P. performed experiments.

Competing interests The authors declare no competing interests.

Author Information Reprints and permissions information is available at www.nature.com/reprints. The authors declare no competing financial interests. Readers are welcome to comment on the online version of this article. Correspondence and requests for materials should be addressed to D. J. P. (david.j.procter@manchester.ac.uk). 